The prize of 2000 rupees offered in October, 1871 , by the Government of India for the compilation of the best Manual of Family Medicine for India has been awarded to SurgeonMajor Moore, of the Rajpootana Political Agency.

A suM of $£ 10,000$ is to be expended in making improvements, hygienic and otherwise, in the North Surrey District Schools at Anerley. This step will, we hope, result in the eradication of ophthalmia, so long prevalent among the children.

THE Town Council of Portsmouth have resolved to memorialise the Government against the erection of the Hospital for Contagious Diseases which has been commenced close to Portsea.

A commitres of the Leeds Town Council appointed to examine in to the cultivation of grass from sewage products have reported strongly in favour of native guano as a manure.

ENTERIC FEVER has broken out in several parts of Birminghain. Another visit to the town by a Local Government Board inspector will probably be necessary.

A MUNIFICENT gift, in the form of the rentage of a coalfield, has just been made by Archdeacon Hill to the Chesterfield and North Derbyshire Hospital and Dispensary.

YELLOW FEVER is causing great mortality in the State of Louisiana. In some of the towns the deaths amount to twenty a day.

Wr are glad to be able to state that the outbreak of enteric fever at Brighouse, Yorkshire, has been completely arrested.

THE Brighton Free Library was opened last week with an inaugural address by Dr. Carpenter, F.R.S.

\section{THE ASHANTEE WAR.}

IT is melancholy to read of the loss of life, and of such valuable life too, as that attending this miserable war with the Ashantees. Nothing could have surpassed the pluck and daring of officers and men under the circumstances of the late treacherous attack on Commodore Commerell's reconnoitring party up the Prah. Meanwhile great activity prevails at bome. The materials for huts are being shipped, together with stores of all kinds and ammunition for the campaign which, of some kind or another, it is perfectly clear must now be undertaken if we are to retain our position on the Gold Coast. Huts will undoubtedly prove very superior to tents in a climate at a latitude of nine degrees from the equator. The heat at midday is said to be very great, and it is doubtful whether single tents or the tente d'abri, which forms such a portable and convenient method of shelter, would be found to afford sufficient protection against it. From intelligence furnished us from Cape Coast, we learn that the barrack and hospital accommodation, both at that station and Elmina, is utterly inadequate, and the medical officers have recommended the encampment of troops on available sites in the vicinity of these places in preference to the occupation of buildings that are quite unsuitable for the purpose. Of the 110 marine artillerymen who left Portsmouth some three months ago, all but twenty have been invalided, and several of those left behind are now more or less sickly. Much disease has prevailed among the men of the West India Regiment sinco its arrival, and about one-third of the European officers have been attacked with fever or dysentery, and one of their number died of remittent fever after four days' illness. Still, it must be remembered, as in the case of the marines, they were landed, owing to the exigencies of the service on which they were engaged, at the most unhealthy season, through which they have now nearly passed. Our correspondent states that the health of the West India Contingent had shown some signs of improvement of late. Owing to the smallness of the garrison, the military duties were somewhat severe, and the diet of the troops had been increased in amount, at the instigation of the medical service. An expedition was contemplated against the Ashantees with the Houssas, West Indian and native forces at command, supplemented by volunteers, and every arrangement had been made for its execution. Unfortunately, however, this disastrous affair on the Prah river has occurred, and it has probably put an end to the undertaking almost as soon as it had begun. It had been arranged between the military and naval authorities that the forts should be garrisoned by men from the fleet, so as to set the soldiers at liberty to take the field. Our correspondent says that the doctors are very busy, and that the senior medical officer has his hands full in devising sanitary precautions.

Our readers may doubtless remember that we recently published the results of an extensive series of trials in India of various preparations from bark, besides quinine, and that these results were of the most encouraging and satisfactory kind. We understand that a trial is to be made of the effects of sulphate of quinidine as a prophylactic against fever.

It may be interesting to afford our readers some information in regard to the geography of the Gold Coast in the neighbourhood of Cape Coast Castle. A very clear map has just been published by Mr. James Wild, which we would recommend our readers interested in the subject to obtain. The Prah river is varionsly estimated at from eighty to 100 miles from Cape Coast; and it is about the same distance from the Prah to Coomassie. Mansu is between thirty and forty miles from Cape Coast; twenty miles further on is Faysoo, and thirty or forty miles beyond this is the Prab, which is the boundary of the Ashantee and the Protectorate. The size of the river depends on the time of year, for it is, of course, enormously swollen during the rainy season, and the ground in its vicinity a swamp. Then comes a big hill-the Monsi hill-of about 1600 feet elevation, and afterwards Coomassie. Coomassie itself is said to be bealthy, and it would be still more so, probably, but for the presence of a huge place in its central part into which, we are told, the Ashantees cast the heads of their enemies decapitated in battle or slain during some of their plundering raids. Of course, it is yet quite uncertain whether Sir Garnet Wolseley will make any expedition to the interior at all, and, if he does, what will be the route that he will take.

\section{Corespondence.}

"Audi alteram partem."

\section{THE MEDICAL AND SURGICAL HISTORY OF THE AMERICAN WAR.}

To the Editor of The LANCET.

Sir,-Absence on the Continent prevented me from seeing The LANCET of August 30th until to-day. In your notice of the "Medical and Surgical History of the War of the Rebellion" in that number, p. 303, you have referred to the criticism by Dr. Otis on some remarks of mine on the classification of gunshot injuries adopted in the United States' armies during the war. I do not write now for the purpose of entering upon an explanation or defence of $\mathrm{my}$ remarks, but simply to say that you are quite right in supposing that I am not one who would wittingly give umbrage to the members of the United States' army medical service, for which $I$, in common with all who know what they did during the war, have the highest respect; and, further, to assure you that, as far as I am aware, I have not written 
anything which ought to have caused offence. As to the official forms of classification used during the United States' war, which were what I discussed, anyone who will refer to my comments upon them in Vol. 54 of the Medico-Chirurgical Transactions, and who will then examine the Surgical volume of the "History of the War of the Rebellion," will not fail to observe that most of my observations are borne out by the alterations made by Dr. Otis himself in these very forms of classification, be having adopted an arrangement in his tables very similar to that which I adrocated for the primary returns from the field hospitals. I am hoping that a reply to the remarks of Dr. Otis will shortly appear in the American Journal of Medical Sciences. A copy of the "Surgical History of the War of the Rebellion" was kindly sent me by Surgeon-General Barnes, chief of the U.S. Army Medisal Department, in June last. On the same day that I received it, observing the criticism in question, I wrote to Dr. Barnes on the subject. Not receiving a reply, $I$ then wrote some remarks for publication, which I hope may appear in the forthcoming number of the above-named journal. I felt that this course was due to my confrères in the United States after the observations of Dr. Otis, to which you have called attention.

I remain, Sir, yours obediently,

Thomas Longmore, Surgeon-General.

Woolstone, near Netley, Sept. 15th, 1873.

\section{A NTISEPTIC SURGERY.}

To the Editor of The LANCET.

SiR,-As one of the many strangers referred to by Mr. Liater in his letter of the 30th ult.* as having witnessed his practice since Mr. Wood's address was delivered before the British Medical Association, permit me to enter a protest against the sweeping assertion and insinuation contained in his concluding sentence.

In preface, let me remark that for nine months previous to my visit to Mr. Lister's wards I had adopted antiseptic surgery in my own practice at Oldham Infirmary. Notwithstanding that I had omitted no one of those precautions said by Mr. Lister to be necessary to success, and that I had personally, at no small sacrifice of time and convenience, conducted every dressing with the utmost care, I had failed to obtain results in any way better than those $I$ had been accustomed to see in dressing by other methods. It was, therefore, with no small interest that I visited Mr. Lister's wards about a fortnight since, anxious to see if I had failed in any detail, and to discover why his results were so much better than my own.

To my disappointment and mortification, I not only found no precaution used that I had not invariably used myself, but I saw cases looking very much like what I had been accustomed to see in other hospitals, and certainly no better than cases I had just seen in adjoining wards in the same hospital. I found that, at least in two of the cases I saw, inflammation and suppuration had occurred after the application of the dressing, and that these were explained away; in one case by the access of germs, and in the other by the premature removal of a drainage tube! The bare possibility of any failure of the antiseptic system was not for a moment entertained by Mr. Lister in his remarks, and we were asked to believe that in these cases putrefaction had been absent, and to observe what an advantage it was to render putrefaction, as he did, an impossibility. At first my feeling had been simply that of disappointment, but after hearing Mr. Lister dogmatically give utterance to the same old theories we have all seen in his writings of two years since and more, oracularly regardless of all that scientific research has elucidated since then, I left his wards, as any man who conscientiously desired to find out and uphold the truth must have done in my place, with the last remnant of $\mathrm{my}$ belief in Professor Lister dissipated to the winds.

It is to such men as Mr. Wood that the profession must look for trustworthy evidence on such a subject as this. Mr. Wood, it is true, may find that the cares of practice effectually prevent him from spending, as Prof. Lister does, several hours a day in his wards, but no one will suspect him of speaking as he has done without having taken every

\footnotetext{
* Tha Larom, September 6th.
}

practicable precaution in carrying out the system he has been testing. Those of your readers who still retain a lingering belief in the efficacy of antiseptic surgery cannot do better than go to Edinburgh and see for themselves; and $I$ am confident that $I$ will not then be the only one of " the many strangers" (as indeed I know I am not now) who had no hesitation in arriving at an explanation-but a very different explanation from that insinuated by $\mathrm{Mr}$. Lister.

$$
\begin{aligned}
& \text { I am, Sir, yours, \&c., } \\
& \text { Oldham, September 8th, 1873. } \quad \text { GeORGE THOMrson, M.D. }
\end{aligned}
$$

\section{SMALL-POX IN GLASGOW.}

To the Editor of THE LANCET.

SiR,-I observe a "newspaper cutting" in Tre LANCET of September 6th, which you kindly introduce with the hope that it "contains a greatly exaggerated report of the death-rate from small-pox in Glasgow." I am happy to as sure you that it does.

In the first place, the figures given as "rates per 1000 " are actual numbers, and the paragraph should therefore read thus:- "An alarming statement was made at a meeting of the Govan Parochial Board held in Glasgow on Thursday regarding the death-rate. In the Partick district of that parish, for the year ending June, 1873, the deaths from small-pox were ninety-seven, while the average in the other four districts instanced for comparison was under eight."

In the next place, Partick, although a part of the parish of Govan, is not within the municipal boundary of Glasgow, but is an independent burgh. The meaning of this action of the Govan Parochial Board is simply this: that while the four districts referred to for comparison yielded an average of eight deaths each from small-pox in the specified year, their population being 190,380, the district of Partick yielded ninety-seven deaths, its population being only 23,918; and the board appeals to the Board of Supervision to institute an inquiry, alleging that the Pulice Commissioners of Partick have been remiss in the discharge of their duty as local authority.

In Glasgow, since December, 1870, when small-pox first appeared, we have fought a hard but hitherto a successful battle. Out of a population of above half a million, the highest number of deaths registered in any one quarter has been 66 . In the year 1872 we had only 137 . We have unlimited hospital accommodation, a vaccinating station, which yields an abundant supply of lymph, which is taken to the infected localities, and a constant system of house-to-house visitation in those localities. We resort to compulsory removal whenever it is necessary, and insist upon disinfection and washing of clothing being done at our own establishment, not in common washing houses. I have no doubt that these special measures, along with the general operations of the sanitary staff, account sufficiently for the striking contrast between the prevalence of smallpox in many suburban districts, such as Partick, and the comparative immunity of this large urban population. I am, Sir, your obedient servant,

Glangow, 8th Sept., 1873.

$$
\text { JAMES B. RUSSELL, M.D., }
$$
Medical Officer.

\section{ON THE PREVENTIVE TREATMENT OF URIC-ACID CALCULT. \\ To the Editor of THE LANCET.}

Sir,-In a paper on the above subject read by Dr. Harley during the recent meeting of the British Medical Association in London, the following passages occur:- "The common idea was that the action of the alkalies in the uric-acid diathesis was solely and purely a chemical one. There no doubt existed a chemical action, and that a most important one; but beyond this there was an important physiological action produced in the body, through which the oxidation process was so much increased as to transform the little soluble uric acid into the very soluble urea. To Dr. Basham was owed the establishment of this as a clinical fact."

I take leave to inform Dr. Harley that, in ascribing this explanation to Dr. Basham, I believe him to be in error, as 